\title{
Subclinical hypothyroidism in children: is it always subclinical?
}

\author{
R. Gallizzi, C. Crisafulli, T. Aversa, G. Salzano, F. De Luca, M. Valenzise* and G. Zirilli
}

\begin{abstract}
Aim of this commentary is to report current knowledges on the main clinical and metabolic abnormalities which might be observed in children with longstanding and untreated subclinical hypothyroidism (SH) and to comment the most recent views about natural evolution of thyroid function in the cases with either idiopathic or Hashimoto's thyroiditis-related $\mathrm{SH}$. On the basis of these preliminary remarks, the essential guidelines for an appropriate and tailored management of SH children are also proposed.
\end{abstract}

\section{Background}

Subclinical hypothyroidism $(\mathrm{SH})$ is a condition that is also known as isolated hyperthyrotropinemia [1] and is characterized by serum TSH levels above the upper limit of the reference range, in presence of normal FT4 concentrations [2].

In adults $\mathrm{SH}$ is a relatively common disorder, which may be encountered in 4-20\% of cases and shows a tendency to progress to overt hypothyroidism [3]. Moreover, it is frequently associated with important adverse effects, such as insulin resistance [4], dyslipidemia [5], diastolic and endothelial dysfunction $[3,6]$, coronary disease and heart failure [7-10]. Therefore, replacement therapy with L-T4 is frequently recommended for adult patients with either TSH serum concentrations $>10 \mathrm{~m} \mathrm{IU/l}$ or TSH $<10 \mathrm{~m}$ IU/l and symptoms suggestive of thyroid failure [11, 12].

In children, on the contrary, $\mathrm{SH}$ seems to be less common, with a prevalence that has been reported to range around 1,7\% [13]. Furthermore, several pediatric studies suggest that $\mathrm{SH}$ is a benign and remitting condition, with a negligible risk of progression to overt hypothyroidism [14] and controversial association with adverse health outcomes [15]. Therefore, the benefits of L-T4 treatment in children are clear only for the severe form of $\mathrm{SH}$, whilst they are very uncertain for the mild forms [15]. However, although the available findings are insufficient to recommend replacement therapy for all the children with mild and asymptomatic $\mathrm{SH}$, nevertheless current literature

\footnotetext{
* Correspondence: mvalenzise@unime.it

UOC Pediatria, Department of Human Pathology of Adulthood and Childhood, University of Messina, via Consolare Valeria, 98125 Messina, Italy
}

highlights the potential need for assessment of the subtle abnormalities, which may be associated with even modest increase in serum TSH levels [15].

This commentary aims to review current knowledges on the main clinical and metabolic abnormalities that might be observed in children with longstanding and untreated $\mathrm{SH}$, in order to shed further light on the advantages of an individually tailored therapeutic management of the young patients with this disorder.

\section{Neurocognitive outcome}

Thyroid hormones $(\mathrm{TH})$ are known to play a pivotal role in the regulation of brain maturation and function. In fact, newborns and infants with untreated hypothyroidism are at risk of permanent mental retardation. Furthermore, even children aged more than three years at the time of hypothyroidism onset are at risk of developing subtle cognitive impairment, although TH-dependent brain development is already complete at that age.

According to the results of the few cross-sectional studies aiming to evaluate the influence of $\mathrm{SH}$ on cognitive function, the only subtle negative effects which may be observed in SH children concern attention level $[16,17]$, whereas cognitive performance has been reported to be absolutely normal in these children $[13,16,17]$.

According to the results of the only prospective and case-control study on this topic, no differences seem to exist in verbal, performance and full-scale IQ scores, between SH children and a control group matched for socioeconomic status [18]. Moreover, no relationships were detected between IQ scores and either severity or duration of $\mathrm{SH}$ and no significant differences between $\mathrm{SH}$ 
children and controls were found, even in terms of psychologic and behavioural assessments [18].

Therefore, it is possible to infer, on the basis of the current literature on this issue, that $\mathrm{SH}$ is unable to negatively affect cognitive function, at least in childhood. This inference is also supported by the results of the small and short-term study by Aijaz et al. [16], according to which L-T4 treatment does not seem to be able to improve the attention problems that had been found in the children with untreated $\mathrm{SH}$.

\section{Linear growth}

$\mathrm{TH}$ are well assessed to play an important part in the regulation of growth and bone maturation; therefore, short stature and bone age retardation are recognized as two common manifestations of untreated overt hypothyroidism.

By contrast, no impairment in linear growth and bone maturation is generally reported in children with mild $\mathrm{SH}$. In fact, height, growth velocity and bone maturation in a series of 36 children with longstanding $\mathrm{SH}$ were found to be normal and to not differ from those detected in an age-matched control population [18]. Furthermore, no changes in height velocity were documented in a large cohort of children with idiopathic and mild SH, who were followed for two years [19].

Finally, from the analysis of the current studies on the auxological repercussions of $\mathrm{SH}$, it may be argued that a growth failure might be observed only among $\mathrm{SH}$ children with very severe thyroid dysfunction (TSH $>50 \mathrm{~m} \mathrm{IU/l}$ and T4 levels at the low limit of the reference range), whilst no negative impact on growth velocity is detectable in children with mild SH [15].

\section{Bone health status}

It is generally accepted that thyroid status, as well as genetic, ethnic, nutritional and lifestyle factors, is able to significantly affect bone mineral homeostasis,. Whereas hyperthyroidism increases bone turnover and the risk of osteoporosis [20], hypothyroidism reduces bone turnover, thus favouring a gain in bone mass and mineralization [21]. However, studies on large adult populations documented an increased risk of fractures in both the patients with overt hyperthyroidism and those with overt hypothyroidism [22, 23].

To the best of our knowledge, there is only one study aiming to investigate the bone mineral status in children with $\mathrm{SH}$. On the basis of this study results, the authors concluded that bone health, as assessed both at lumbar spine and at phalanges of the hand, is not impaired in untreated children and adolescents with long lasting SH [24]. This inference has been subsequently highlighted by Salerno et al. in a recent review aiming to analyze the metabolic and clinical risk factors associated with $\mathrm{SH}$ in childhood [15].

\section{Obesity}

It is well known that a biochemical picture of isolated hyperthyrotropinemia may be observed in around $10-23 \%$ of obese children [25], a relative prevalence which is distinctly higher than that generally reported in the pediatric general population, i.e. 1.7\% [13].

The pathophysiological mechanisms which may be responsible for such a relationship between $\mathrm{SH}$ and obesity in pediatric age have not been clarified so far. However, it has been found that thyroid function may often normalize after weight loss [25]. Therefore, it is generally believed that $\mathrm{SH}$ is a consequence, rather than a cause, of weight gain [15].

It has to be emphasized, however, that the association between $\mathrm{SH}$ and obesity might play a key-role in conditioning an increased risk for metabolic syndrome. Indeed, both waist circumference and waist-to-height ratio were reported to be more elevated among obese children with mild $\mathrm{SH}$ than among their euthyroid counterparts and to correlate with TSH serum levels [26, 27].

\section{Cardiovascular function}

$\mathrm{SH}$ in childhood has been reported to be associated with an increased risk of hypertension, whose prevalence was found to be significantly higher in $\mathrm{SH}$ children than in euthyroid controls $[28,29]$. Nevertheless, these findings were not subsequently confirmed by other authors [26].

In adult patients $\mathrm{SH}$ was reported to be able to impair both flow-mediated dilation and intima-media thickness $[6,30]$. By contrast, the only case control and prospective study about the effects of $\mathrm{SH}$ on vascular function in pediatric age failed to demonstrate any significant alterations in flow-mediated dilation and intima media thickness among 39 children with mild but long lasting idiopathic $\mathrm{SH}$ [31]. It has to be underlined that the children with $\mathrm{SH}$, when compared with 39 euthyroid controls, exhibited, at entry, increased concentrations of asymmetric dimethylarginine, i.e. an aminoacid which may be considered as an early marker of endothelial dysfunction [31]. Serum levels of this aminoacid were subsequently found to normalize after 2 years of L-T4 therapy, thus suggesting that mild and untreated $\mathrm{SH}$ might be associated with early changes in pro-atherogenic profile [31]. In fact, although the $\mathrm{SH}$ children included in that study did not exhibit a biochemical picture of overt dyslipidemia, nevertheless the subtle alterations in HDL-cholesterol $(C)$ and in triglycerides/ HDL-C ratio, that were found at entry are incline to favour the onset of an atherosclerotic process. It is noteworthy that these alterations regressed under L-T4 treatment [31].

Similar proatherogenic abnormalities had been previously reported also by other authors, who investigated the relationships between $\mathrm{SH}$ and cardiovascular risk factors by cross-sectional study designs. Also the results of those studies suggested that TSH might be implicated in the regulation 
of both lipid profile and blood pressure, irrespectively of $\mathrm{TH}$ action [26, 32].

It might also be postulated that the proatherogenic abnormalities, which have been documented in SH children, could be ascribed to the presence of confounding factors, such as obesity and inflammation. Nevertheless, a multivariate analysis, aiming to identify the major determinants of the proatherogenic alterations found in $\mathrm{SH}$ children, revealed that the most independent factor associated with cardiovascular risk was the duration of SH [26]. On the basis of this finding, it was argued that longstanding untreated SH may be able to play a direct role on early atherosclerotic changes, not mediated by either visceral adiposity or other confounding factors [26].

\section{Natural course of SH}

The most important factor, which is known to be able to affect the natural history of $\mathrm{SH}$, is its etiology: either idiopathic or secondary to HT.

In the children with no underlying thyroid disorders natural evolution is characterized by a spontaneous normalization of thyroid function tests in a large majority of cases [33]. Therefore, idiopathic SH may be considered as a remitting or self-limiting process, with low risk of progression toward overt hypothyroidism [34, 35]. A deterioration of thyroid status over time might be predicted, at the time of $\mathrm{SH}$ diagnosis, in the cases with associated celiac disease and in those with initial presence of goiter and elevated thyroglobulin autoantibodies [36]. Baseline TSH levels, however, are probably the most powerful predictors of SH evolution over time [37, 38].

Whereas in children with idiopathic $\mathrm{SH}$ the risk of worsening their thyroid status over time is very low and the probability of a spontaneous TSH normalization is high, longitudinal course is very different in children with HT-related SH [33, 39, 40]. Furthermore, the children with HT-related SH have been found to be more exposed to the risk of developing a pathological enlargement of thyroid gland throughout follow-up [39], an adverse event which might be successfully counteracted with L-t4 therapy.

On overall, on the basis of the results of these prospective studies, it can be inferred that the association with HT is able to exert, per se, a negative impact on the long-term evolution of $\mathrm{SH}$, irrespective of other concomitant risk factors [39]. Such a negative impact may be furtherly exacerbated by the coexistence of either Turner syndrome (TS) or Down's syndrome (DS) [33], i.e. two relatively common chromosomopathies that are known to be associated with an increased risk of HT [41]. It is noteworthy that, in a significant percentage of DS children with HTrelated $\mathrm{SH}, \mathrm{SH}$ may progress over time to hyperthyroidism [33], a metamorphosis which may be observed, more rarely, even in children with no chromosomopathies [42].

\section{To treat or not to treat?}

The question of whether individuals with $\mathrm{SH}$ should be treated or not is still controversial, owing to the lack of case-control studies documenting significant benefits of L-T4 treatment on hypothyroid symptoms, life quality, cardiovascular function and metabolic abnormalities [43]. It has to be clarified, however, that the decision of what to do regarding these patients should be based, in the first place, on patients' age. In fact, a therapeutical policy is more justified, on the whole, for the adult patients with $\mathrm{SH}$, who are more incline to deteriorate their thyroid status over time. By contrast, the risk of progressing from $\mathrm{SH}$ to overt hypothyroidism is distinctly lower in children and adolescents. Furthermore, cardiovascular and metabolic complications have been reported to have a more severe clinical expression in adults than in children [6,30,31].

Other aspects which have to be evaluated, when an endocrinologist considers the opportunity of starting L$\mathrm{T} 4$ therapy in $\mathrm{SH}$ patients, concern the severity of thyroid dysfunction. In many pediatric centres, in fact, treatment is initiated for persistent elevations $>10 \mathrm{mIU} / \mathrm{L}$ or for progressively increasing TSH serum levels [44].

Finally, it has to be considered whether $\mathrm{SH}$ is idiopathic or HT-related. In this last event, in fact, the risk of a thyroid status deterioration over time is distinctly higher, especially in the children with a concomitant DS or TS and therefore a close monitoring of thyroid function is mandatory. On the contrary, in the children with neither underlying thyroid disorders, nor associated autoimmune diseases, nor chromosomopathies, the risk of a thyroid status worsening is not very high and the hypothesis of a treatment should be taken into consideration only in the cases with hypothyroid clinical symptoms, or thyromegaly, or very elevated TSH serum levels at entry [36]. In fact, in the patients with idiopathic $\mathrm{SH}$, the evidence for a benefit of L-T4 supplementation is very limited, at least in pediatric age [44]. The only study comparing the effects of treatment versus no therapy in children with idiopathic SH seems to suggest that L-T4 therapy is unable to modify post-treatment outcomes of hyperthyrotropinemia and to prevent the risk of a further TSH increase after treatment withdrawal [38].

\section{Conclusions}

SH in children and adolescents may not be always asymptomatic. In a limited number of cases with longstanding $\mathrm{SH}$, cardiovascular abnormalities and proatherogenic metabolic alterations may be sporadically observed, especially in the patients with associated obesity. The risk of such complications should be considered when a decision about the management of $\mathrm{SH}$ has to be taken. It is also important to consider whether $\mathrm{SH}$ is idiopathic or HT-related. Furthermore, it should be considered the possible association with other factors, that are known to exert a negative impact on the long-term evolution of this disorder. 


\section{Abbreviations}

C: Cholesterol; DS: Down's syndrome; HT: Hashimoto's thyroiditis; LT4: Levo-thyroxine; SH: Subclinical hypothyroidism; TS: Turner syndrome

\section{Acknowledgements}

Not applicable.

\section{Funding}

This research did not receive any specific grant from any funding agency in the public, commercial or not-for-profit sector.

\section{Availability of data and materials}

Not applicable.

\section{Authors' contributions}

MV and FDL have written the paper; RG, GC and GS have organized the materia and prepared its distribution in the different sections; TA and GZ have collected references. All authors read and approved the final manuscript.

\section{Ethics approval and consent to participate}

Not applicable

\section{Consent for publication}

Not applicable.

\section{Competing interests}

The authors declare that they have no competing interests.

\section{Publisher's Note}

Springer Nature remains neutral with regard to jurisdictional claims in published maps and institutional affiliations.

\section{Received: 22 December 2017 Accepted: 7 February 2018} Published online: 17 February 2018

\section{References}

1. Van Vliet G, Deladoëy J. Interpreting minor variations in thyroid function or Echostructure: Treating Patients, Not Numbers or Images. Pediatr Clin North Am. 2015;62(4):929-42

2. Biondi B, Cooper DS. The clinical significance of subclinical thyroid dysfunction. Endocr Rev. 2008;29(1):76-131.

3. Cooper DS, Biondi B. Subclinical thyroid disease. Lancet. 2012;379(9821): 1142-54.

4. Maratou E, Hadjidakis DJ, Kollias A, Tsegka K, Peppa M, Alevizaki M, et al. Studies of insulin resistance in patients with clinical and subclinical hypothyroidism. Eur J Endocrinol. 2009;160(5):785-90.

5. Duntas LH, Wartofsky L. Cardiovascular risk and subclinical hypothyroidism focus on lipids and new emerging risk factors. What is the evidence? Thyroid. 2007;17(11):1075-84

6. Gao N, Zhang W, Zhang YZ, Yang Q, Chen SH. Carotid intima-media thickness in patients with subclinical hypothyroidism: a meta-analysis. Atherosclerosis. 2013;227(1):18-25.

7. Razvi S, Weaver JU, Vanderpump MP, Pearce SH. The incidence of ischemic heart disease and mortality in people with subclinical hypothyroidism: reanalysis of the Whickham Survey cohort. J Clin Endocrinol Metab. 2010;95(4):1734-40.

8. Rodondi N, den Elzen WP, Bauer DC, Cappola AR, Razvi S, Walsh JP, et al. Thyroid Studies Collaboration. Subclinical hypothyroidism and the risk of coronary heart disease and mortality. JAMA. 2010:304(12):1365-74.

9. Gencer B, Collet TH, Virgini V, Bauer DC, Gussekloo J, Cappola AR, et al. Thyroid studies collaboration Subclinical thyroid dysfunction and the risk of heart failure events: an individual participant data analysis from 6 prospective cohorts. Circulation. 2012;126(9):1040-9.

10. Chaker L, Baumgartner C, den Elzen WP, Ikram MA, Blum MR, Collet TH, et al. Subclinical Hypothyroidism and the Risk of Stroke Events and Fatal Stroke: An Individual Participant Data Analysis. J Clin Endocrinol Metab. 2015;100(6):2181-91.

11. Garber JR, Cobin RH, Gharib H, Hennessey JV, Klein I, Mechanick Jl, et al. Clinical practice guidelines for hypothyroidism in adults: cosponsored by the American Association of Clinical Endocrinologists and the American Thyroid Association. Thyroid. 2012;22(12):1200-35.
12. Pearce SH, Brabant G, Duntas LH, Monzani F, Peeters RP, Razvi S, et al. ETA guideline: Management of Subclinical Hypothyroidism. Eur Thyroid J. 2013;2(4):215-28

13. Wu T, Flowers JW, Tudiver F, Wilson JL, Punyasavatsut N. Subclinical thyroid disorders and cognitive performance among adolescents in the United States. BMC Pediatr. 2006;6:12.

14. Monzani A, Prodam F, Rapa A, Moia S, Agarla V, Bellone S, et al. Endocrine disorders in childhood and adolescence. Natural history of subclinical hypothyroidism in children and adolescents and potential effects of replacement therapy: a review. Eur J Endocrinol. 2012 Dec 10;168(1):R1-R11.

15. Salerno M, Capalbo D, Cerbone M, De Luca F. Subclinical hypothyroidism in childhood - current knowledge and open issues. Nat Rev Endocrinol. 2016:12(12):734-46

16. Aijaz NJ, Flaherty EM, Preston T, Bracken SS, Lane AH, Wilson TA. Neurocognitive function in children with compensated hypothyroidism: lack of short term effects on or off thyroxin. BMC Endocr Disord. 2006;6:2

17. Ergür AT, Taner Y, Ata E, Melek E, Bakar EE, Sancak T. Neurocognitive functions in children and adolescents with subclinical hypothyroidism. J Clin Res Pediatr Endocrinol. 2012:4(1):21-4.

18. Cerbone M, Bravaccio C, Capalbo D, Polizzi M, Wasniewska M, Cioffi D, et al. Linear growth and intellectual outcome in children with long-term idiopathic subclinical hypothyroidism. Eur J Endocrinol. 2011;164(4):591-7.

19. Wasniewska M, Salerno M, Cassio A, Corrias A, Aversa T, Zirilli G, et al. Prospective evaluation of the natural course of idiopathic subclinical hypothyroidism in childhood and adolescence. Eur J Endocrinol. 2009; 160(3):417-21.

20. Murphy E, Glüer CC, Reid DM, Felsenberg D, Roux C, Eastell R, et al. Thyroid function within the upper normal range is associated with reduced bone mineral density and an increased risk of nonvertebral fractures in healthy euthyroid postmenopausal women. J Clin Endocrinol Metab. 2010;95(7): 3173-81.

21. Eriksen EF, Mosekilde L, Melsen F. Kinetics of trabecular bone resorption and formation in hypothyroidism: evidence for a positive balance per remodeling cycle. Bone. 1986;7(2):101-8.

22. Vestergaard $P$, Mosekilde L. Fractures in patients with hyperthyroidism and hypothyroidism: a nationwide follow-up study in 16,249 patients. Thyroid. 2002;12(5):411-9.

23. Vestergaard P, Rejnmark L, Mosekilde L. Influence of hyper- and hypothyroidism, and the effects of treatment with antithyroid drugs and levothyroxine on fracture risk. Calcif Tissue Int. 2005;77(3):139-44.

24. Di Mase R, Cerbone M, Improda N, Esposito A, Capalbo D, Mainolfi C, et al. Bone health in children with long-term idiopathic subclinical hypothyroidism. Ital J Pediatr. 2012:38:56.

25. Reinehr T. Thyroid function in the nutritionally obese child and adolescent Curr Opin Pediatr. 2011:23(4):415-20.

26. Cerbone M, Capalbo D, Wasniewska M, Mattace Raso G, Alfano S, Meli R, et al. Cardiovascular risk factors in children with long-standing untreated idiopathic subclinical hypothyroidism. J Clin Endocrinol Metab. 2014;99(8): 2697-703.

27. Zhang J, Jiang R, Li L, Li P, Li X, Wang Z, et al. Serum thyrotropin is positively correlated with the metabolic syndrome components of obesity and dyslipidemia in chinese adolescents. Int J Endocrinol. 2014;2014:289503.

28. Chen $\mathrm{H}$, Xi Q, Zhang H, Song B, Liu X, Mao X, et al. Investigation of thyroid function and blood pressure in school-aged subjects without overt thyroid disease. Endocrine. 2012;41(1):122-9.

29. Ittermann T, Thamm M, Wallaschofski H, Rettig R, Völzke H. Serum thyroidstimulating hormone levels are associated with blood pressure in children and adolescents. Clin Endocrinol Metab. 2012;97(3):828-34

30. Taddei S, Caraccio N, Virdis A, Dardano A, Versari D, Ghiadoni L, et al. Impaired endothelium-dependent vasodilatation in subclinical hypothyroidism: beneficial effect of levothyroxine therapy. J Clin Endocrinol Metab. 2003;88(8):3731-7.

31. Cerbone M, Capalbo D, Wasniewska M, Alfano S, Mattace Raso G, Oliviero U, et al. Effects of L-thyroxine treatment on early markers of atherosclerotic disease in children with subclinical hypothyroidism. Eur J Endocrinol. 2016; 175(1):11-9

32. Nader NS, Bahn RS, Johnson MD, Weaver AL, Singh R, Kumar S. Relationship between thyroid function and lipid status or insulin resistance in a pediatric population. Thyroid. 2010:20:1333-9.

33. Wasniewska M, Aversa T, Salerno M, Corrias A, Messina MF, Mussa A, et al. Fiveyear prospective evaluation of thyroid function in girls with subclinical mild hypothyroidism of different etiology. Eur J Endocrinol. 2015;173(6):801-8. 
34. De Luca F, Santucci S, Corica D, Pitrolo E, Romeo M, Aversa T. Hashimoto's thyroiditis in childhood: presentation modes and evolution over time. Ital J Pediatr. 2013;39:8.

35. Valenzise M, Aversa T, Zirilli G, Salzano G, Corica D, Santucci S, De Luca F. Analysis of the factors affecting the evolution over time of subclinical hypothyroidism in children. Ital J Pediatr. 2017;43(1):2.

36. Radetti G, Maselli M, Buzi F, Corrias A, Mussa A, Cambiaso P, et al. The natural history of the normal/mild elevated TSH serum levels in children and adolescents with Hashimoto's thyroiditis and isolated hyperthyrotropinaemia: a 3-year follow-up. Clin Endocrinol. 2012;76(3):394-8.

37. Lazar L, Frumkin RB, Battat E, Lebenthal Y, Phillip M, Meyerovitch J. Natural history of thyroid function tests over 5 years in a large pediatric cohort. J Clin Endocrinol Metab. 2009;94(5):1678-82.

38. Wasniewska M, Corrias A, Aversa T, Valenzise M, Mussa A, De Martino L, et al. Comparative evaluation of therapy with $L$-thyroxine versus no treatment in children with idiopathic and mild subclinical hypothyroidism. Horm Res Paediatr. 2012;77(6):376-81.

39. Aversa T, Valenzise M, Corrias A, Salerno M, De Luca F, Mussa A, et al. Underlying Hashimoto's thyroiditis negatively affects the evolution of subclinical hypothyroidism in children irrespective of other concomitant risk factors. Thyroid. 2015;25(2):183-7.

40. Aversa T, Corrias A, Salerno M, Tessaris D, Di Mase R, Valenzise M, et al. FiveYear Prospective Evaluation of Thyroid Function Test Evolution in Children with Hashimoto's Thyroiditis Presenting with Either Euthyroidism or Subclinical Hypothyroidism. Thyroid. 2016;26(10):1450-6.

41. Aversa T, Lombardo F, Valenzise M, Messina MF, Sferlazzas C, Salzano G, et al. Peculiarities of autoimmune thyroid diseases in children with Turner or Down syndrome: an overview. Ital J Pediatr. 2015;41:39.

42. Wasniewska M, Corrias A, Arrigo T, Lombardo F, Salerno M, Mussa A, et al. Frequency of Hashimoto's thyroiditis antecedents in the history of children and adolescents with graves' disease. Horm Res Paediatr. 2010;73(6):473-6.

43. Villar HC, Saconato H, Valente O, Atallah AN. Thyroid hormone replacement for subclinical hypothyroidism. Cochrane Database Syst Rev. 2007;3:CD003419.

44. O'Grady MJ, Cody D. Subclinical hypothyroidism in childhood. Arch Dis Child. 2011;96(3):280-4.

\section{Submit your next manuscript to BioMed Central and we will help you at every step:}

- We accept pre-submission inquiries

- Our selector tool helps you to find the most relevant journal

- We provide round the clock customer support

- Convenient online submission

- Thorough peer review

- Inclusion in PubMed and all major indexing services

- Maximum visibility for your research

Submit your manuscript at www.biomedcentral.com/submit 